\title{
Determinação dos parâmetros anatômicos, físico-químico e fitoquímicos das folhas de Solanum lycocarpum A. St.- Hill
}

GALLON, M.E.1*; BARROS, B.S.P.'; SILVA, M.A.'; DIAS, S.H.M.'; ALVES-DA-SILVA, G.1

-Universidade Federal de Alfenas, Laboratório de Plantas Medicinais e Fitoterápicos, Departamento de Alimentos e Medicamentos, rua Gabriel Monteiro da Silva, 700, Cep: 37130-000, Alfenas-MG, Brasil. *Autor para correspondência: mariliagallon@hotmail.com.br

\begin{abstract}
RESUMO: A espécie vegetal Solanum lycocarpum, Solanaceae, popularmente conhecida como lobeira, está distribuída por todo o Brasil, principalmente em áreas do cerrado. Estudos comprovam que os frutos possuem diversas atividades e, atualmente, estão sendo utilizados no tratamento da diabetes. As folhas são utilizadas popularmente contra afecções das vias urinárias, cólicas abdominais e renais, espasmos e epilepsia, porém são poucos os estudos científicos que verificam as atividades farmacológicas das folhas. Assim, torna-se necessária a determinação de parâmetros anatômicos, físico-químicos e fitoquímicos que auxiliarão em futuras identificações e controle de qualidade da droga vegetal. Neste estudo foi realizada a coleta, secagem e pulverização das folhas de Solanum lycocarpum para a obtenção da droga vegetal e posterior caracterização desta. As análises microscópicas do pecíolo, nervura central e mesofilo revelaram características típicas da família Solanaceae, observando-se um sistema vascular bicolateral e a presença de areia cristalina e tricomas estrelados. A triagem fitoquímica, constatou a presença de taninos, flavonoides, esteróides e triterpenos, cumarinas e saponinas. Obteve-se o teor médio de $9,90 \%$ de perda por dessecação, $7,91 \%$ de cinzas totais e de $0,37 \%$ de cinzas insolúveis em ácidos. Para as substâncias extraíveis por álcool, o teor médio encontrado foi de $14,479 \%$ para o método de extração por Soxhlet e $0,987 \%$ para o método de extração a frio. Assim, espera-se que esses dados possam ser utilizados na identificação e controle de qualidade da droga vegetal de Solanum lycocarpum para a produção de novos medicamentos fitoterápicos.
\end{abstract}

Palavras chave:Solanum lycocarpum, parâmetros analíticos, Solanaceae.

\begin{abstract}
Determination of the anatomics, physical-chemicals and phytochemicals parameters of the Solanum lycocarpum A.St.-Hill leaves. The plant species Solanum lycocarpum, Solanaceae, most known as lobeira, are distributed throughout Brazil, especially in Cerrado areas. Studies show that the fruits own different properties and, currently, are being used in the treatment of diabetes. Even though the leaves are being used by the general population against urinary tract disorders, renal and abdominal cramps, spasms and epilepsy, there are few scientific studies that verify the possible pharmacological activities of leaves. This shows that it is necessary to research and determinate the anatomic, physical-chemicals and the phytochemicals parameters that are going to help in the identification and quality assurance of the drug. In this study the leaves of Solanum lycocarpum were collected, dried and pulverized in order to be obtained the plant drug for further characterization.. Microscopic analyzes of the petiole, midrib and mesophyll showed typical features of the Solanaceae family, by detecting a biocolateral vascular system and the presence of crystallines and and stellatetrichomes. In the phytochemical screening performed, the tanning, flavonoids, sterols and triterpenes, coumarins and saponins were found. We obtained an average grade of $9.90 \%$ loss on the drying, total ash of $7.91 \%$ and $0.37 \%$ of ash insoluble in acids. . For the substances extractable through alcohol, the average content found was $14.479 \%$ for the Soxhlet extraction method and $0.987 \%$ for the cold extraction method. This data can be used in the identification and quality assurance of the plant drugs of Solanum lycocarpum for the production of new herbal medicines.
\end{abstract}

Keywords: Solanum lycocarpum. Analytical parameters. Solanaceae.

Recebido para publicação em 03/10/2014

Aceito para publicação em 01/04/2015

10.1590/1983-084X/14_127

Rev. Bras. PI. Med., Campinas, v.17, n.4, supl. II, p.937-944, 2015. 


\section{INTRODUÇÃO}

As plantas medicinais são usadas no tratamento e cura de enfermidades desde a antiguidade (Di Stasi, 1996). Pela sua riqueza química e farmacológica, têm sido alvo de crescentes estudos com o objetivo de comprovar atividades atribuídas pelas crenças populares ou mesmo obter novos compostos ativos (Menendez-Baceta et al., 2015). O uso de medicamentos fitoterápicos está se tornado popular pois, quando feito de forma adequada, apresenta pouco ou nenhum efeito colateral, quando comparado aos medicamentos tradicionais; além disso, as plantas medicinais têm sido amplamente usadas em cosméticos e nutracêuticos (Rokaya et al., 2014).

A tendência atual é de exigir dos insumos fitofarmacêuticos o atendimento aos critérios de qualidade, o que se traduz pela padronização física, química e biológica dos produtos obtidos. Essa abordagem é hoje mundialmente empregada na obtenção dos insumos fitofarmacêuticos, garantido a eficácia, segurança e a qualidade dos medicamentos fitoterápicos obtidos (ANVISA, 2010).

Os extratos obtidos de produtos naturais sofrem frequentemente oscilações nas concentrações dos metabólitos. Dessa maneira, o emprego de técnicas analíticas para a caracterização da droga vegetal torna-se importante para garantir que os extratos tenham a mesma quantidade de substâncias ativas (Simões, 2007).

Neste contexto, esta pesquisa tem como objetivo fornecer parâmetros anatômicos, físico-químicos e fitoquímicos das folhas de Solanum lycocarpum que poderão ser utilizados na identificação e controle de qualidade da droga vegetal, auxiliando estudos que comprovem novas atividades farmacológicas.

\section{cológica}

Características botânica, química e farmaSolanum lycocarpum pertence ao reino Plantae, divisão Magnoliophyta, classe Magnoliopsida, ordem Solani, família Solanaceae, gênero Solanum e espécie Solanum lycocarpum (Souza \& Lorenzi, 2005). É popularmente conhecida como lobeira ou fruta-de-lobo e está amplamente distribuída pelo cerrado brasileiro, sendo também encontrada nos estados do Paraná, Rio de Janeiro, Pará e Amazonas (Lorenzi \& Matos, 2008).

A lobeira é uma planta nativa do Brasil e é considerada uma espécie daninha das pastagens, sendo encontrada em beiras de estradas e terrenos baldios. Possui porte arbustivo ou arbóreo, caule tortuoso provido de acúleos, apresentando preferência por solos ácidos e arenosos. As flores florescem entre os meses de maio a julho (Souza \& Lorenzi, 2005).
Em regiões endêmicas, as populações rurais utilizam os frutos da lobeira no preparo de geléias e doces, sendo empregados também como remédios caseiros por possuir atividade diurética, calmante, antiespasmódica, antiofídica e antiepilética. As folhas são usadas na forma de chá, obtido por decocção, e são recomendadas contra afecções das vias urinárias, cólicas abdominais e renais, espasmos e epilepsia (Lorenzi \& Matos, 2008).

O polvilho obtido a partir dos frutos tem sido amplamente empregado no controle da diabetes e da obesidade, além de ser eficaz na redução dos níveis de colesterol (Leite \& Oliveira, 2007). Esse polvilho também é utilizado em afecções hepáticas (Vila Verde et al, 2003).

Diversos estudos farmacológicos têm sido feitos principalmente com os frutos de Solanum lycocarpum na tentativa de identificar atividades antiinflamatórias, antioxidantes, antiparasitárias, analgésicas e tóxicas, bem como os possíveis efeitos alelopáticos e hepatotoxicidade provocada pela planta (Lorenzi \& Matos, 2008).

Nos frutos da lobeira foram encontrados majoritariamente dois glicoalcaloides, a solasonina e a solamargina. Tais glicoalcaloides têm sido citados pelo seu efeito citotóxico contra linhagens de células tumorais. (Tiossi, 2010; Munari et al., 2014).

Entre os nutrientes encontrados nos frutos de Solanum lycocarpum destacam-se: vitamina C, sacarose, fósforo e ferro (Miranda, 2010). Também foram identificadas cinco saponinas esteroidais, liconosídeos la, Ib, II, III e IV e um pseudoalcalóide esteroidal oligoglicosídeo, denominado lobofrutosídeo (Nakamura et al., 2008).

\section{MATERIAL E MÉTODOS Obtenção da droga vegetal Coleta \\ O material vegetal foi coletado no mês} de março na Fazenda Ponte Alta no município de Alfenas-MG, com determinação do GPS (S $21^{\circ} 25^{\prime}$ $13^{\prime \prime}$ e $\mathrm{O} 45^{\circ}$ 52' 20". Elevação: $836 \mathrm{~m}$ ).

A coleta do material vegetal foi realizada em duas etapas: a) coleta de material vegetal florido, que foi enviado para a identificação taxonômica e preparação de exsicatas pelo Herbário da Universidade Federal de Alfenas (Departamento de Botânica) onde as mesmas foram depositadas (Voucher UALF 190); b) coleta de material vegetal, especificamente das folhas da planta, que foi utilizada posteriormente nos experimentos sob a forma de droga vegetal. 


\section{Secagem e Pulverização}

As partes coletadas da espécie vegetal, previamente divididas, separadas e dispostas em camadas finas, foram submetidas à secagem em estufa de ar circulante a $45^{\circ} \mathrm{C}$ durante dois dias. As folhas secas obtidas foram submetidas à divisão grosseira, seguida por pulverização em moinho de facas e padronização do tamanho das partículas.

\section{Determinação dos parâmetros anatômi- cos, físico-químico e fitoquímicos}

\section{Caracterização macroscópica}

Analisou-se o tamanho, cor, superfície, textura e fratura da droga vegetal, de acordo com a quinta edição da Farmacopéia Brasileira (2010).

\section{Caracterização microscópica}

O material vegetal foi incluído em historresina e seccionado em cortes transversais em micrótomo Leica $^{R}$, com espessura de 7 micrômetros. Os cortes histológicos foram colocados em lâminas de vidro e fixados utilizando calor. Após a coloração com azul de toluidina à $0,1 \%$ por 30 segundos, realizouse a montagem entre lâmina e lamínula utilizando entellan para a confecção das lâminas permanentes.

\section{Observação da epiderme foliar}

As folhas de Solanum lycocarpum foram seccionadas em pequenos pedaços e colocadas em solução de ácido acético glacial e água oxigenada $20 \mathrm{~V}(1: 1)$ sob aquecimento em chapa aquecedora a $60^{\circ} \mathrm{C}$ até a epiderme se destacar. Após a separação das epidermes superior e inferior, estas foram lavadas com água destilada, coradas com azul de toluidina e colocadas entre lâmina e lamínula para a análise da epiderme e classificação dos estômatos de acordo com a quinta edição da Farmacopéia Brasileira (2010).

\section{Triagem fitoquímica}

Foram realizados testes fitoquímicos para a detecção de taninos, catequinas, flavonoides, glicosídeos cardíacos, esteróides e triterpenóides, derivados da cumarina, saponinas, alcaloides e antraquinonas. Os procedimentos utilizados seguiram os descritos por Simões et al (2007) e Matos (1997).

\section{Determinação de perda por dessecação}

A determinação de perda por dessecação foi realizada de acordo com a quinta edição da Farmacopéia Brasileira (2010).

Determinação de cinzas totais e cinzas insolúveis em ácido

As determinações de cinzas totais e insolúveis foram realizadas de acordo com a quinta edição da Farmacopéia Brasileira (2010). por álcool

Determinação de substâncias extraíveis

Utilizou-se o método de extração por Soxhlet e extração a frio, de acordo com a quinta edição da Farmacopéia Brasileira (2010).

\section{RESULTADOS E DISCUSSÃO}

\section{Droga vegetal \\ Caracterização macroscópica \\ O limbo apresentou 14,5 a 19 centímetros} de comprimento e 5 a 7 centímetros de largura. Para o pecíolo, as medidas variaram de 1 a 2 centímetros (Figura 1).

A face adaxial da droga vegetal possui coloração verde musgo escuro, enquanto a face abaxial possui uma coloração mais pálida de verde. Foram observadas manchas marrom-amareladas nas regiões onde há a presença de acúleos. Os pecíolos apresentaram coloração marromamarelada.

A superfície da droga vegetal possui tricomas e acúleos aciculares que acompanham a inervação. A face adaxial é tomentosa, pubescente e possui tricomas estrelados pedicelados; a face abaxial é rugosa e pubescente, com tricomas estrelados longos e pedicelados.

\section{Caracterização microscópica Pecíolo}

Em secção transversal, o pecíolo apresentou epiderme uniestratificada, constituídas por células justapostas e cutícula fina, com tricomas estrelados. Em sequência, aparecem 8 a 10 camadas de células de colênquima com espessamento do tipo lacunar, com presença intensa de areia cristalina. Logo após, ocorre o parênquima fundamental constituído por células de paredes finas celulósicas e isodiamétricas com espaços do tipo meato e areia cristalina. Em todos os tecidos, exceto na epiderme, foi identificado um grande número de células escurecidas devido à concentração de areia cristalina. O sistema vascular é do tipo bicolateral constituído por um feixe maior central e dois menores axilares (Figura 2 e 3 ).

Em cortes transversais do pecíolo de Solanum lycocarpum, Araújo et al. (2010) descreveu o colênquima como sendo do tipo angular. Porém, de acordo com a análise efetuada pode-se concluir que o colênquima é do tipo lacunar.

\section{Nervura principal}

Em corte transversal, a nervura principal apresenta epiderme adaxial uniestratificada, com células justapostas de contorno arredondo e cutícula fina e com tricomas em candelabro. Logo abaixo, 


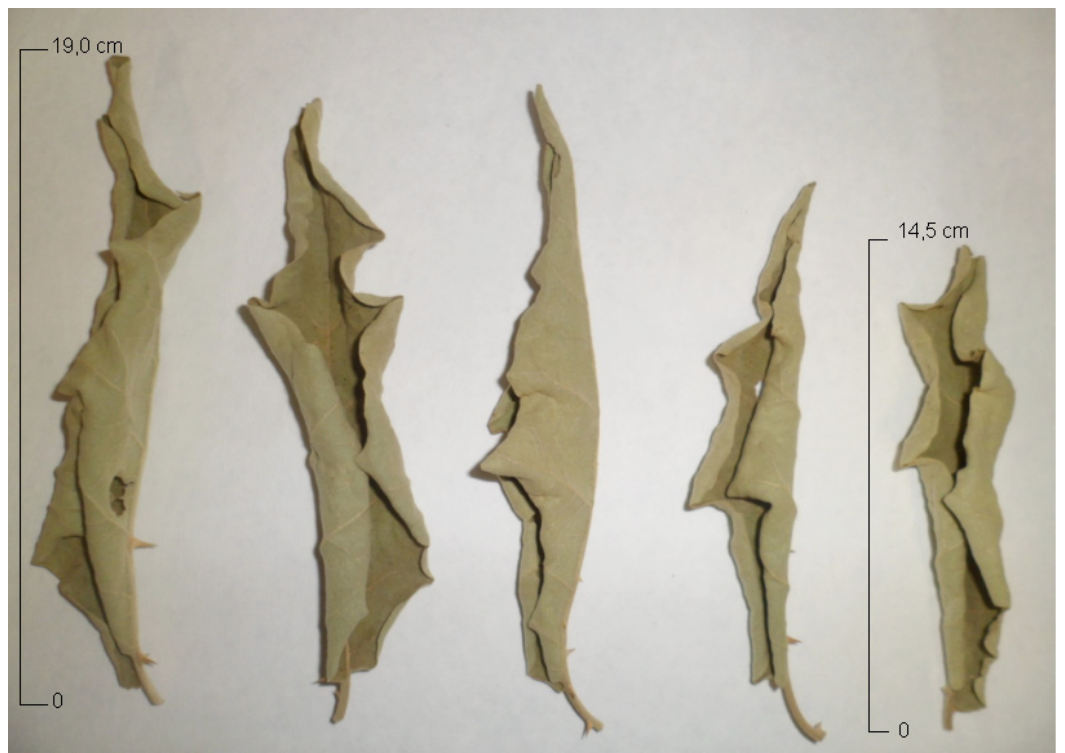

FIGURA 1. Tamanho médio das folhas da droga vegetal de Solanum lycocarpum

observa-se 5 a 7 camadas de células constituindo o colênquima lacunoso e, em sequência o parênquima fundamental, constituído por células de paredes finas e celulósicas e espaço tipo meato, com areia cristalina. O feixe vascular é bicolateral, disposto em forma de arco (Figura 4 e 5).

\section{Mesofilo}

Em corte transversal, o mesofilo apresentou epiderme constituída por uma única camada de células justapostas e tabulares, com cutícula mais espessa na face adaxial e mais fina na da face abaxial. Observou-se a presença de tricomas estrelados e estômatos em ambas as faces da epiderme (Figura 6).

O mesofilo é dorsiventral, constituído por uma camada de parênquima paliçádico atingindo aproximadamente $50 \%$ do mesofilo. O restante do mesofilo é constituído por parênquima lacunoso, no qual foi identificada a intensa presença de inclusões do tipo areia cristalina. Tais achados foram similares aos encontrados por Elias et al (2003) em folhas jovens de Solanum lycocarpum. Assim, pode-se concluir que as folhas jovens e adultas de Solanum lycocarpum possuem grande semelhança.

\section{Epiderme foliar}

Em secção paradérmica, a epiderme abaxial apresentou células sinuadas de parede fina com presença de grande número de tricomas estrelados. E estômatos anisocíticos, anomocíticos e paracíticos. A epiderme adaxial é constituída por células poligonais de parede fina, também apresenta grande quantidade de tricomas estrelados, porém em menor número do que na epiderme abaxial, e estômatos anisocíticos, anomociticos e paraciticos (Figura 7).

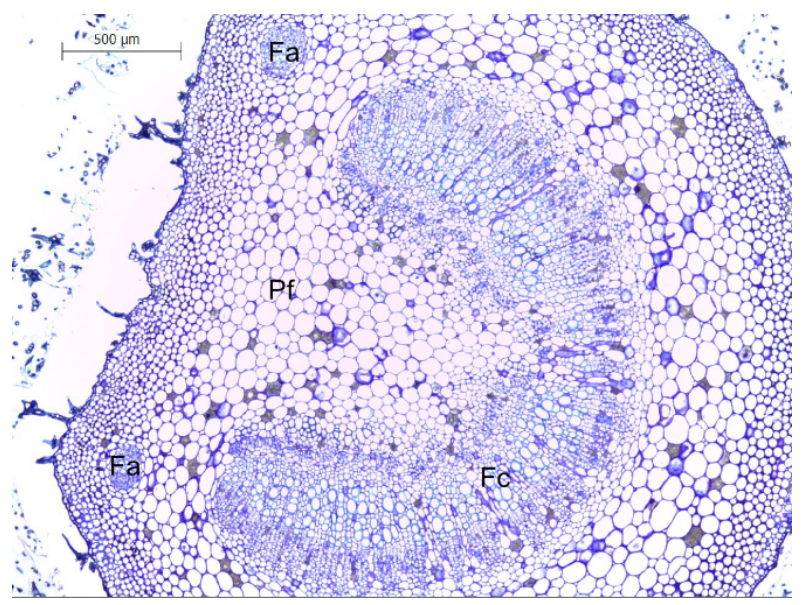

FIGURA 2. Corte transversal do pecíolo de Solanum lycocarpum em aumento de 4x. Feixes axilares (Fa), feixe central $(F c)$ e parênquima fundamental $(P f)$.

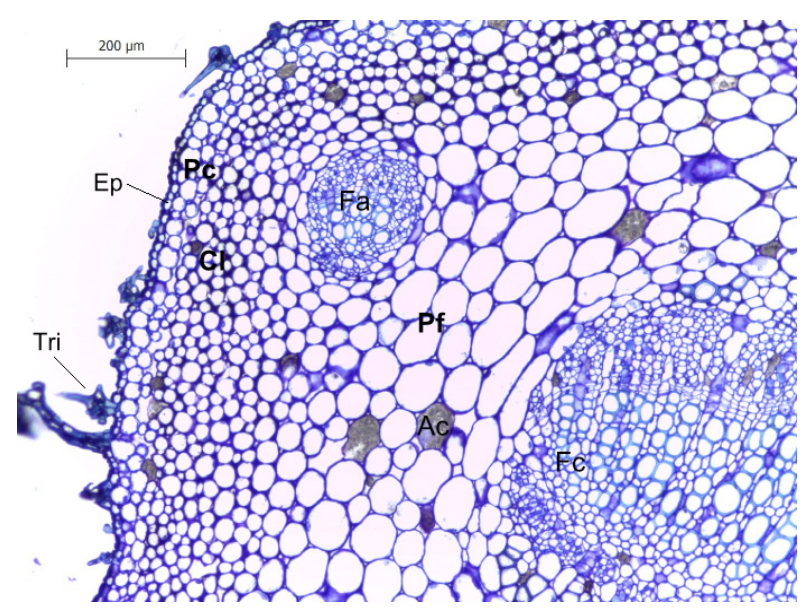

FIGURA 3. Corte transversal do pecíolo de Solanum lycocarpum em aumento de 10x. Tricomas estrelados (Tri), epiderme (Ep), parênquima clorofiliano (Pc), colênquima lacunar $(\mathrm{Cl})$, parênquima fundamental $(\mathrm{Pf})$, feixe axilar ( $\mathrm{Fa})$, feixe central $(\mathrm{Fc})$ e areia cristalina $(\mathrm{Ac})$. 


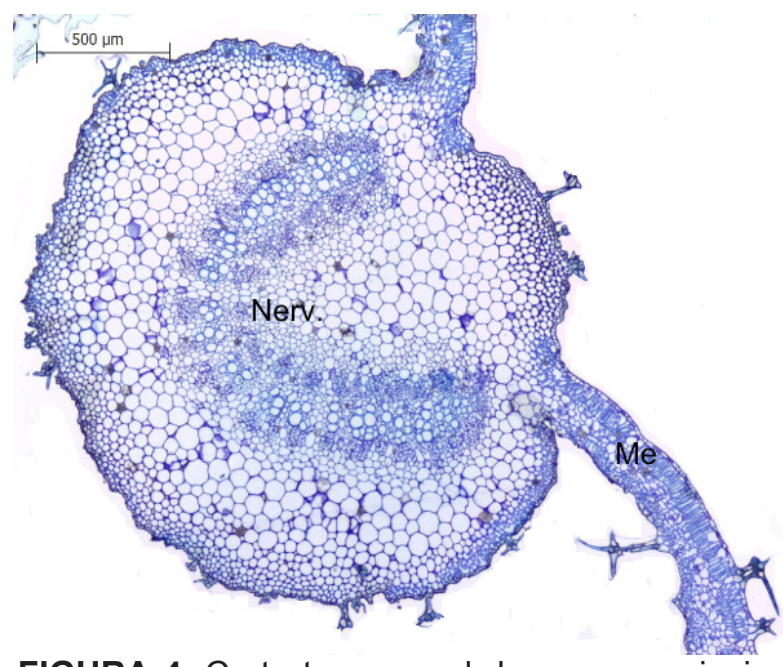

FIGURA 4. Corte transversal da nervura principal e mesofilo, em aumento de 4x. Nervura principal (Nerv.) e mesofilo (Me).

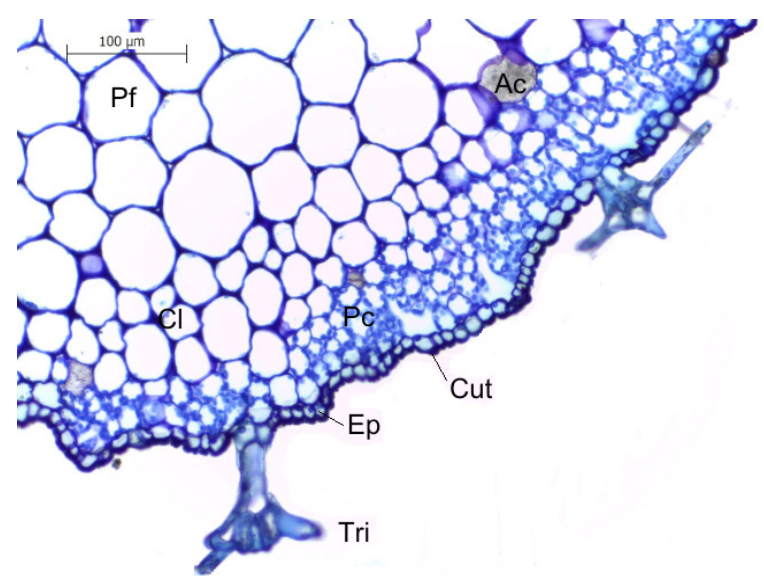

FIGURA 5. Corte transversal da nervura principal de Solanum lycocarpum em aumento de 20x. Tricomas estrelados (Tri), epiderme (Ep), cutícula (Cut), parênquima clorofiliano ( $\mathrm{Pc}$ ), colênquima lacunar $(\mathrm{Cl})$, parênquima fundamental $(\mathrm{Pf})$ e areia cristalina (Ac).

Segundo Elias et al. (2003), as folhas de Solanum lycocarpum são anfiestomáticas, possuindo estômatos anomocíticos, anisocíticos e paracíticos. Tal descrição foi condizente com o observado neste estudo. Porém, o mesmo autor relatou a presença de tricomas glandulares, os quais não foram identificados na análise microscópica realizada.

\section{Triagem fitoquímica}

A partir da triagem fitoquímica, constatouse a presença de taninos, flavonoides, esteróides e triterpenos, cumarinas e saponinas (Tabela 1).

$\mathrm{Na}$ pesquisa de taninos, as reações com cloreto férrico, de precipitação de proteínas, de

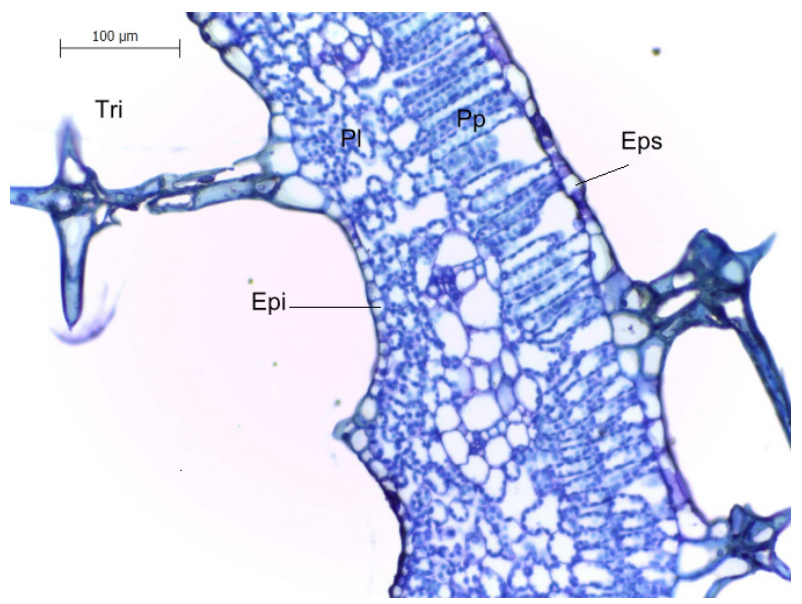

FIGURA 6. Corte transversal do mesofilo em aumento de 20x. Tricomas estrelados (Tri), epiderme inferior (Epi), epiderme superior (Eps), parênquima paliçádico $(\mathrm{Pp})$ e parênquima lacunar $(\mathrm{PI})$.

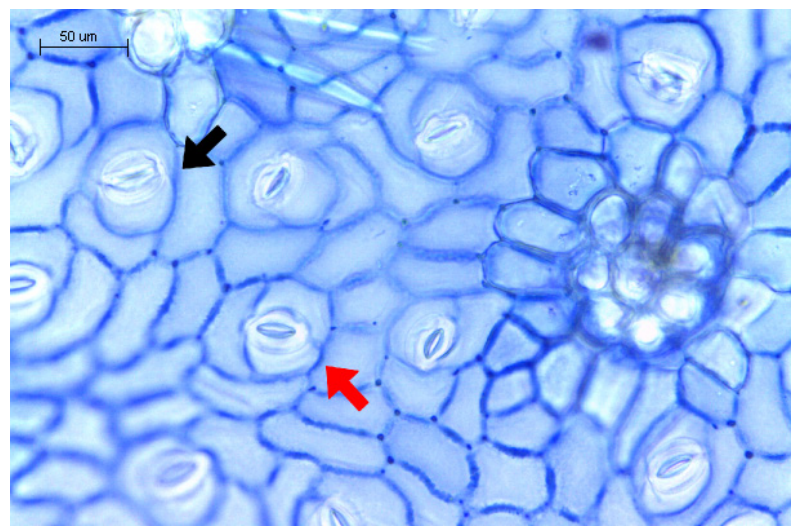

FIGURA 7. Epiderme de Solanum lycocarpum em corte transversal, em aumento de 40x. A seta preta indica um estômato paracítico e a seta vermelha um estômato anisocítico.

precipitação de alcaloides e com acetato de cobre apresentaram resultado positivo, indicando a presença de taninos hidrolisáveis na droga vegetal. Porém, não foram detectados taninos condensados.

A presença de saponinas na droga vegetal foi detectada pela formação de espuma persistente e resistente a ácidos minerais diluídos e pela presença de material insolúvel, indicando a hidrólise ácida das saponinas com consequente insolubilidade das sapogeninas. Na pesquisa realizada por Nakamura et al., (2008) foram identificadas, nos frutos de Solanum lycocarpum, cinco saponinas esteroidais (liconosídeos la, Ib, II, III e IV) e um pseudoalcalóide esteroidal oligoglicosídeo; dessa maneira, podemos inferir que a constituição química das folhas de Solanum lycocarpum está relacionada com a de seus frutos.

As folhas de Solanum lycocarpum são 
TABELA 1. Resultados da triagem fitoquímica

\begin{tabular}{|c|c|c|}
\hline Pesquisa & Reação & Resultado \\
\hline Taninos & $\begin{array}{l}\text { Cloreto férrico } \\
\text { Precipitação de proteínas } \\
\text { Precipitação de alcaloides } \\
\text { Acetato de cobre } \\
\text { Taninos condensados }\end{array}$ & $\begin{array}{l}+ \\
+ \\
+ \\
+ \\
-\end{array}$ \\
\hline Catequinas & Vanilina e ácido clorídrico & - \\
\hline Flavonoides & $\begin{array}{l}\text { Cloreto de alumínio } \\
\text { Cloreto férrico }\end{array}$ & $\begin{array}{l}+ \\
+\end{array}$ \\
\hline Glicosídeos cardiotônicos & $\begin{array}{l}\text { Liebermann-Burchard } \\
\text { Salkowski } \\
\text { Baljet } \\
\text { Keller-Kiliani }\end{array}$ & $\begin{array}{l}- \\
- \\
- \\
-\end{array}$ \\
\hline Esteróides e triterpenos & Anidrido acético e ácido sulfúrico & + \\
\hline Derivados de cumarinas & Hidróxido de alumínio & + \\
\hline Saponinas & $\begin{array}{l}\text { Formação de espuma persistente } \\
\text { Hidrólise ácida }\end{array}$ & $\begin{array}{ll}+ \\
+ \\
+\end{array}$ \\
\hline Alcaloides & $\begin{array}{l}\text { Reativo de Bouchardat } \\
\text { Reativo de Dragendorff } \\
\text { Reativo de Bertrand } \\
\text { Reativo de Mayer }\end{array}$ & $\begin{array}{l}- \\
- \\
- \\
-\end{array}$ \\
\hline Antraquinonas & $\begin{array}{l}\text { Bornträger direta } \\
\text { Bornträger indireta para O-glicosídeos } \\
\text { Bornträger indireta para C-glicosídeos }\end{array}$ & $\begin{array}{l}- \\
- \\
-\end{array}$ \\
\hline
\end{tabular}

Legenda: + significa resultado positivo para a respectiva reação e - significa resultado negativo.

utilizadas popularmente contra afecções das vias urinárias. Tal finalidade pode ser atribuída à presença de taninos, já que estes possuem ação antibacteriana, antifúngica e antiviral. Essas atividades são devido à habilidade dos taninos de complexarem com macromoléculas, como proteínas e polissacarídeos (Simões et al, 2007).

\section{Determinação de perda por dessecação}

De acordo com a análise realizada, obtevese o teor médio de 9,90\% de perda por dessecação em relação a droga vegetal seca ao ar (Tabela 2).

TABELA 2. Resultados para a determinação de perda por dessecação

\begin{tabular}{cc}
\hline Amostra & Teor (\%) \\
\hline 1 & 9,78 \\
2 & 9,97 \\
3 & 9,94 \\
\hline
\end{tabular}

Legenda: Teor refere-se a perda por dessecação da droga vegetal em cada análise, medido em percentagem.

Determinação de cinzas totais e de cinzas insolúveis em ácido

A partir dos resultados encontrados, obtevese média de $7,91 \%$ de cinzas totais (Tabela 3 ).
Obteve-se média de cinzas insolúveis em ácido de $0,37 \%$ na droga vegetal (Tabela 4). Esses valores indicam a presença de minerais na droga vegetal.

TABELA 3. Resultados para a determinação de cinzas totais

\begin{tabular}{cc}
\hline Amostra & Teor $(\%)$ \\
\hline 1 & 8,04 \\
2 & 7,95 \\
3 & 7,74 \\
\hline
\end{tabular}

Legenda:Teor refere-se ao teor de cinzas totais a droga vegetal em cada análise, medido em percentagem.

TABELA 4. Resultado para a determinação de cinzas insolúveis em ácido

\begin{tabular}{cc}
\hline Amostra & Teor (\%) \\
\hline 1 & 0,33 \\
2 & 0,36 \\
3 & 0,43 \\
\hline
\end{tabular}

Legenda: $m$ refere-se à massa final após a incineração, em gramas; Teor refere-se ao teor de cinzas insolúveis em na droga vegetal em cada análise, medido em percentagem. 


\section{Determinação de substâncias extraíveis por álcool}

A partir dos dados obtidos foi possível calcular o teor de substâncias extraíveis por álcool em relação a droga vegetal seca. Este teor foi calculado para cada amostra utilizada, sendo obtida uma média de 14,479\% (Tabela 5).

Utilizando o método de extração a frio, o teor de substâncias extraíveis por álcool foi menor do que no método de extração por Soxhlet. Obtevese média de $0,987 \%$ de substâncias extraíveis por álcool em relação a droga vegetal seca (Tabela 6).

TABELA 5. Dados utilizados para calcular o teor de substâncias extra

\begin{tabular}{cc}
\hline Amostra & $\mathrm{T}(\%)$ \\
\hline 1 & 12,959 \\
2 & 16,086 \\
3 & 14,392 \\
\hline
\end{tabular}

Legenda: T representa o teor de substâncias extraíveis por álcool, expresso em porcentagem.

TABELA 6. Dados utilizados para calcular o teor de substâncias extraíveis por álcool pelo método de extração a frio

\begin{tabular}{cc}
\hline Amostra & $\mathrm{T}(\%)$ \\
\hline 1 & 0,974 \\
2 & 0,993 \\
3 & 0,994 \\
\hline
\end{tabular}

Legenda: T representa o teor de substâncias extraíveis por álcool, expresso em porcentagem.

\section{CONCLUSÃO}

A caracterização de drogas vegetais através da determinação de parâmetros analíticos é importante para garantir que os extratos tenham a mesma quantidade de substâncias ativas e auxiliar em identificações e controle de qualidade da mesma. Isto é essencial para que se obtenha um produto fitofarmacêutico que apresente reprodutibilidade e constância dos efeitos biológicos.

Conclui-se, que a droga vegetal de Solanum lycocarpum apresenta como principais características: limbo com coloração verde musgo na face adaxial e verde pálida na face abaxial; superfície com tricomas e acúleos; pecíolo com epiderme uniestratificada, cutícula fina, tricomas estrelados e colênquima com espessamento do tipo lacunar, com presença intensa de areia cristalina; mesófilo dorsiventral, constituído por parênquima paliçádico e por parênquima lacunoso, com intensa presença de areia cristalina.

A triagem fitoquímica possibilitou a identificação de metabólitos secundários responsáveis pelas diversas atividades atribuídas pela crença popular. Observou-se a presença de taninos, flavonoides, derivados de cumarina, saponinas, esteróides e triterpenos. Estudos comprovam que os taninos possuem ação antibacteriana, antifúngica e antiviral, podendo ser os responsáveis pela utilização contra afecções das vias urinárias.

Obteve-se um teor médio de $9,90 \%$ de umidade, $7,91 \%$ de cinzas totais e de $0,37 \%$ de cinzas insolúveis em ácidos em relação à droga vegetal seca. Para as substâncias extraíveis por álcool, o teor médio encontrado foi de $14,479 \%$ e $0,987 \%$ para os métodos de extração por Soxhlet e a frio respectivamente.

Esses dados mostram que as folhas de Solanum lycocarpum possuem vários metabólitos ativos, sendo importante a realização de novos estudos para comprovar as atividades terapêuticas observadas empiricamente e propiciar a produção de novos medicamentos fitoterápicos.

\section{AGRADECIMENTOS}

À Universidade Federal de Alfenas (UNIFAL); ao Conselho Nacional de Desenvolvimento Científico e Tecnológico (CNPq) e à FAPESP Projeto BIOTAFAPESP (09/52237-9).

\section{REFERÊNCIAS}

ARAÚJO, N.D. et al. Estudo farmacobotânico comparativo de folhas de Solanum crinitum Lam., Solanum gomphodes Dunal e Solanum lycocarpum A. St.Hil.,Solanaceae. Revista Brasileira de Farmacognosia, v.20, n. 5, p. 666-674, 2010.

BRASIL. Ministério da Saúde. Agência Nacional de Vigilância Sanitária. Resolução - RDC n 14, de 31 de março de 2010. Dispõe sobre o registro de medicamentos fitoterápicos. Diário Oficial da União. Brasília, 5 abr. 2010. Seção 1, p.85-87.

DI STASI, L. C. Plantas medicinais - arte e ciência: um guia de estudo interdisciplinar. 1ed. São Paulo: UNESP, 1996. 230 p.

ELIAS, S.R.M. et al. Anatomia foliar em plantas jovens de Solanum lycocarpum A.St.-Hil. (Solanaceae). Revista Brasileira de Botânica, v. 26, n.2, p.169-174, 2003.

BRASIL. Farmacopeia Brasileira. 5 ed., São Paulo: Atheneu, 2010. p. 192-199, v.1.

LEITE, D.S.; OLIVEIRA, S.C.C. Efeito de folhas de Solanum lycocarpum St. A Hil. e a influência de diferentes matrizes e idade das folhas no crescimento de Sesamun indicum L. Revista Brasileira de Biociências, v. 5, p. 1083-1085, 2007.

LORENZI, H.; MATOS, F. J.A. Plantas medicinais no Brasil. 2 ed. Nova Odessa: Instituto Plantarum, 2008. $544 p$.

MATOS, F. J. A. Introdução à fitoquímica experimental.

Rev. Bras. PI. Med., Campinas, v.17, n.4, supl. II, p.937-944, 2015. 
2 ed. Fortaleza: Edições UFC, 1997. 141p.

MENENDEZ-BACETA, G. et al. The importance of cultural factors in the distribution of medicinal plant knowledge: A case study in four Basque regions. Journal of Ethnopharmacology, v.161, p.116-127, 2015.

MIRANDA, M.A. Avaliação do potencial antiparasitário do extrato alcaloídeo e de alcaloides esteroidais dos frutos de Solanum lycocarpum A. St.-Hil. 2010. 110p. Dissertação (Mestrado - Área de Concentração em Produtos Naturais e Sintéticos) - Faculdade de Ciências Farmacêuticas de Ribeirão Preto, Universidade de São Paulo, Ribeirão Preto.

MUNARI, C.C. et al. Antiproliferative activity of Solanum lycocarpum alkaloidic extract and their constituents, solamargine and solasonine, in tumor cell lines. Journal of Natural Medicines, v.68, p.236-241, 2014.

NAKAMURA, S. et al. Steroidal and pseudoalkaloid oligoglycoside from Brazilian natural medicine, "fruta do lobo" (fruit of Solanum lycocarpum). Phytochemistry, v.69, p.1565-1572, 2008.

ROKAYA, M.B. et al. Traditional uses of medicinal plants in gastrointestinal disorders in Nepal. Journal of Ethnopharmacology, v.158, p.221-229, 2014.

SIMÕES, C. M. O.; SCHENKEL, E. P.; GOSMANN, G.; MELLO, J. C. P.; MENTZ, L. A.; PETROVICK, P. R., Farmacognosia: da planta ao medicamento. 6 ed. Florianópolis: UFSC; Porto Alegre: UFRGS, 2007. $1096 \mathrm{p}$

SOUZA, V. C.; LORENZI, H. Botânica sistemática. 1 ed. Nova Odessa: Instituto Plantarum, 2005. 640p.

TIOSSI, R.F.J. Obtenção do extrato padronizado de Solanum lycocarpum A. St.-Hil contendo glicoalcaloides, desenvolvimento de método analítico por CLAE e de forma farmacêutica de uso tópico. 2010. 134p. Dissertação (Mestrado - Área de Concentração em Produtos Naturais e Sintéticos) - Faculdade de Ciências Farmacêuticas de Ribeirão Preto, Universidade de São Paulo, Ribeirão Preto.

VILA VERDE, G.M. et al. Levantamento etnobotânico das plantas medicinais do cerrado utilizadas pela população de Mossâmedes (GO). Revista Brasileira de Farmacognosia, v. 13, p. 64-66, 2003. 